fluctuations. Until the natural fluctuations in fish population are adequately understood, their limits determined, and the causes which give rise to them discovered, a trustworthy verdict as to the effect of fishing is difficult to obtain.

If such problems as these are to be solved the in- vestigation of the sea must proceed on broadly conceived lines, and a comprehensive knowledge must be built up, not only of the natural history of the fishes, but also of the many and varied conditions which influence their lives. The life of the sea must be studied as a whole.

\title{
The Efficiency of Man and the Factors which influence it. ${ }^{1}$
}

\section{By Prof. E. P. Cathcart, M.D., D.Sc., F.R.S.}

$\mathrm{T}^{\mathrm{H}}$ E subject of my address--the efficiency of the human organism and the factors which influence this efficiency-is, in my opinion, one of the most important problems of the present day. It is a problem which cannot, however, be considered only from its physiological aspect if it is to receive adequate consideration; its implications are much wider, reaching right down to the very basis of our daily lives. As I am no expert in industry or economics, I shall confine my attention so far as possible to the problem from the physiological side, and leave to others the sociological application.

The term "efficiency" has become a mere catchword, bandied about by people who have not the faintest idea of what the word connotes. Practically it has come to mean, to the average man in the street, the mythical improvement which is to be anticipated from some change in workshop or office organisationa bigger and better result at a smaller cost. The word has a very definite meaning in engineering science, and this meaning has been transferred from the inanimate machine to the living organism. In the case of the engine, the problem is relatively simple, as the number of interfering factors is not great, but the solution of the problem in the case of the organism is beset with many difficulties, as the interfering factors are numerous and varied. Two types of efficiency are spoken of in connexion with the animal body. One type is the mechanical efficiency in the engineering sense, i.e. the ratio which exists between the heat equivalent of the external muscle work done and the energy output of the subject during the performance of the work in question. This is a problem which has attracted many workers, and there seems to be a general consensus of opinion that the efficiency of man in the performance of external work is about 20 per cent. gross and 25 per cent. net. The other type of efficiency is that which is called industrial or productive efficiency, where the capacity of the individual to perform effective work is dealt with, judging the capacity of the individual by, for example, his output in unit time, So far as the worker himself is concerned, the whole object in industrial efficiency, is undoubtedly to get the greatest output with the minimum of effort. The determination of the mechanical efficiency is fairly readily carried out; but it is very difficult to get an accurate gauge of the industrial efficiency. At bottom they are closely related, and both are physiological problems.

The leaders of industry have not been slow to accept and utilise the gains of science in the realm of inanimate:

${ }^{1}$ From the presidential address delivered to Section 1 (Physiology) of the British Association at Hull on Sept. 8. things, but they have been slow to recognise the fact that there is a science of physiology which deals with the man who controls the productive machinery. New inventions may completely revolutionise shop equipment, good machines may be replaced by better, and better by still better, but man remains almost as immutable as the ages. Physiological evolution is infinitely slow, and man has not yet become "an affectionate machine-tickling aphid."

It is but a little more than a hundred years since this country was industrialised, and we are still reaping the aftermath of the terrible conditions which then reigned, when the great centres of industry were swamped with country dwellers who poured into the towns in the race for wealth. Few realise the hopelessly unphysiological conditions which developed in the methods of work, the hours and conditions of work, the housing. The following citation from Robert Owen gives a good idea of the conditions ruling in the early years of last century in one of our staple industries: "In the manufacturing districts it is common for parents to send their children of both sexes at seven or eight years of age, in winter as well as summer, at six o'clock in the morning, sometimes, of course, in the dark, and occasionally amidst frost and snow, to enter the manufactories which are often heated 'to a high temperature, and contain an atmosphere far from being the most favourable to human life, and in which all those employed in them very frequently continue until twelve o'clock at noon, when an hour is allowed for dinner, after which they return to remain, in a majority of cases, till eight o'clock at night."' Six till eight, with a break of one hour : a fourteen hours' day, and fifteen was not unknown. Owen, in the article from which I have quoted, was petitioning Parliament, asking what?. That a twelve hours' day be instituted, to include one and a half hours for meals, and that no child should be employed until the age of ten was reached. He pointed out in the course of the article that the results from the manufacturers' point of view would be better with a twelve hours' day (i.e. that the industrial efficiency, in modern words, would be improved).

Yet we wonder that the offspring of stock descended from workers under these conditions, which certainly. improved as the century advanced, but were far from ideal, gave the high yield of $\mathrm{C}_{3}$ lads recorded in the National Service Report. We might have been prepared for the disclosure, as the pre-war records of countries with conscription showed that the number of rejections for the Army of town and factory workers was far in excess of those for men drawn from country districts. But evidence of the state of the national 
physique is not confined to these war figures. Sir George Newman, in his valuable and interesting Report on Preventive Medicine, has directed attention to the enormous amount of time which is annually lost through sickness. The minimum average amounted to I4,295,724 weeks (or a period upwards of 270,000 years) of sickness per annum, and this figure did not include absence from work due to maternity benefit, sanatorium treatment, or absence for less than four days per patient. This is the evidence of the National Health Insurance.

The design of the organism which has to stand the strain is not at fault. It is an organism which, in the language of the engineer, is abundantly supplied with factors of safety, and has an over-all high factor of safety. The body is not designed merely to perform the minimum amount of work or to stand the minimum strain; there is always a reserve. The perfect coordination of the different parts of the organism is required, because the human being is capable of intense muscular exertion for short periods. The intensity of the work is, as a general rule, inversely proportional to the length of time during which it must be carried out.

If, in the human organism, we were concerned merely with the co-ordinated action of a series of effectors, with the capacity of a certain group of muscles to perform a given amount of work, the solution of the problem would be relatively simple. But we are dealing with a living organism, capable not only of doing work, but of repairing the worn-out parts; as and when required. Further, we are dealing with an organism which varies not only in its capacity to perform work, but in its "will to work." We are dealing with a subtle organism which has a whole series of protective mechanisms at its command, an organism which can be fatigued and rendered useless, as a working unit, by an amount of work on a particular day which on another day it can perform with the utmost ease and without apparent fatigue.

The efficiency of a man is not merely dependent on the amount of work which can be performed by his muscles; the circulatory, respiratory, and nervous systems are of equal importance, and all are intimately related. In spite of the many and varied stresses and strains to which the organism is subjected in the course of life, as the result of the many factors of safety, unless the overloading is excessive, too frequent or too long continued, the organism, so long as it remains physiological, is practically unaffected by ordinary' hard work.

If we turn now to the consideration of the factors which influence the efficiency, both in the mechanical and the industrial sense, we find that the main controlling factor is undoubtedly the condition known as fatigue. Fatigue is a word just as frequently used as efficiency, and yet it is almost impossible to give an accurate definition of the term. Generally speaking, it is to be regarded as the antithesis of efficiency.

The study of the metabolism has given little or no clue so far to the real nature of fatigue. Benedict and I carried out a certain amount of experimental work on this phase of the question. Our results show that the subject may be on the very verge of absolute collapse, and yet, so far as the metabolic determination goes, there is no very marked evidence of diminished efficiency in a mechanical sense. In an experiment with
M. A. M., who, in the post-absorptive state, rode on a bicycle ergometer for nearly four and a half hours until on the verge of collapse, doing 208,000 kilogrammetres of external work during the time, the metabolism was determined six times during the riding period with the following result :

TABLE I.

\begin{tabular}{|c|c|c|c|c|c|}
\hline \multicolumn{3}{|c|}{ Time. } & $\begin{array}{l}\text { Oxygen Con- } \\
\text { sumption per } \\
\text { min. in c.c. }\end{array}$ & $\begin{array}{l}\text { Rate of Work, } \\
\text { revs, per min. }\end{array}$ & $\begin{array}{l}\text { Net Efficiency } \\
\text { in per cent. }\end{array}$ \\
\hline \multicolumn{6}{|c|}{8.30 A.M. (start) } \\
\hline 9.00 & ", & $\cdot$ & 1967 & $9 \mathrm{I} \cdot 3$ & $23 \cdot I$ \\
\hline 9.45 & ", & . & 1946 & $9 I \cdot 4$ & $23 \cdot 3$ \\
\hline 10.30 & ", & . & 1969 & $9 \mathrm{r} \cdot 7$ & $23 \cdot 2$ \\
\hline II.I 5 & , & . & I948 & $90 \cdot 3$ & $23 \cdot 2$ \\
\hline 12.00 & noon & . & 2003 & $89 \cdot 0$ & $2 x \cdot 7$ \\
\hline $\mathrm{I} 2.45$ & P.M. & & I 899 & $78 \cdot 2$ & $21 \cdot 3$ \\
\hline
\end{tabular}

It will be noted, as might be expected, that there is some slowing of the rate at which the work is done, but the diminution in the net efficiency, in spite of the fact that the subject admitted he was completely done at the conclusion of the last determination, is not striking.

Obviously, then, the capacity to carry on is limited by the genesis of fatigue. But it is equally obvious in practice that a man may be engaged in strenuous labour for many hours without acute signs of impending exhaustion. How is this condition attained? There are at least four factors which, to my mind, play predominant rôles in the attainment of maximum efficiency, namely, the rate of the performance of work, the amount of rest offered or taken by the subject, the rhythm with which the work is performed, and the work habits developed by the worker. Although I shall attempt to examine each of these factors separately, it is not to be inferred that they can really be considered as independent phenomena. As a matter of fact, they are all intimately related, and usually merge into one another.

Of these four factors probably most attention has been devoted to the rate or speed at which work is carried out. Benedict and I found, for example, working with a carefully calibrated bicycle ergometer, that there was a very close connexion between the speed at which work was done and the mechanical efficiency. There was a very definite falling off with increased speed, as the following table shows. Unfortunately it was impossible to get our subject to pedal slower than 70 revolutions per minute.

TABLE II.

\begin{tabular}{|c|c||c|c|}
\hline $\begin{array}{c}\text { Revolutions } \\
\text { per min. }\end{array}$ & Gross Efficiency. & $\begin{array}{c}\text { Revolutions } \\
\text { per min }\end{array}$ & Gross Efficiency. \\
\hline & $20 \cdot 6$ & I I0 & I $7 \cdot 6$ \\
70 & $20 \cdot 0$ & I 20 & I6.9 \\
80 & $19 \cdot 2$ & I30 & I6.I \\
90 & $18 \cdot 4$ & & \\
100 & & \\
\hline
\end{tabular}

We found further that if the amount of effective muscular work done was kept constant, that the efficiency fell with an increase of speed. Thus with effective work equivalent to $\mathrm{x} \cdot 95$ calories performed 
at the rate of 90 and 124 revolutions per minute respectively, with the lower speed the net efficiency was 22.6 per cent., whereas with the higher speed it fell to 15.7 per cent. . Or again, with effective work of $I \cdot 58$ calories at $7 \mathrm{I}$ and $\mathrm{I} 08$ revolutions per minute, the -efficiency was 24.5 per cent. and $I_{5} .6$ per cent. respectively; and finally, with effective work of $\mathbf{I} \cdot 35$ calories at speeds of $7 \mathrm{I}, 94$, and 105 , the efficiencies were $23 . \mathrm{I}$, $20^{\circ} 4$, and $I 7^{\circ} \circ$ per cent.

A. V. Hill has also recently dealt with this problem in a most interesting piece of work, where the activity was strictly confined to the biceps and the brachialis anticus. He demonstrated very clearly that, in spite of the fact that the slower the contraction the greater was the amount of work done, all the advantage thus gained was rapidly neutralised and dissipated as the result of the slow contraction necessarily causing an increased degradation of energy in the way of physiological changes resulting from the maintenance of contraction. It thus followed that a slow contraction, powerful though it might be, was not necessarily one of high efficiency. Hill found that the maximum efficiency was very rapidly attained, the optimum for the muscles investigated being apparently just less than one second, but the fall which followed, as the duration of the contraction increased, was a comparatively slow one. On account, therefore; of the blunt nature of the curve, the efficiency remained more or less constant over a wide range of speeds.

The load has obviously a direct connexion with the speed at which work is done, but it has also a relation to efficiency. Benedict and I found, for example, that both the gross and net efficiencies within the limits of our experiments increased with the load. The probable explanation of this result is that when light work is carried out, maintenance or physiological requirements which have to be covered form a large proportion of the total energy output, a balance which is steadily altered as the amount of external effective work done increases.

On the other hand, when the loads become excessive there is a definite falling off, both in gross and net efficiencies. Laulanié, who also investigated this question, found that at voluntarily selected speeds, with steadily increasing load, the external work done rose with decreasing speed until the load became excessive. He maintained that there were two optima, (a) an economic optimum at 4 kilo. load with high efficiency and a low oxygen consumption per kilogrammetre, and $(b)$ a mechanical optimum between 8 and I2 kilo. load when the output in unit time was highest. The following table from Laulanié makes his point clear :

\section{TABLE III.}

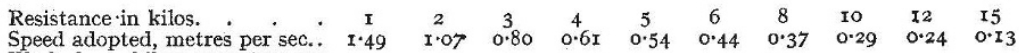

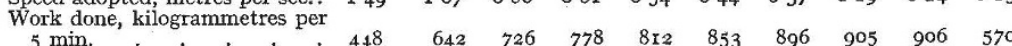

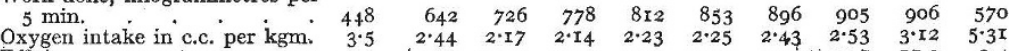
$\begin{array}{lllllllllll}\text { Efficiency per cent. . } & \text {. I I I.I } & 20 \cdot 4 & 22 \cdot 9 & 23 \cdot 3 & 22 \cdot 3 & 22 \cdot 1 & 20 \cdot 4 & 19 \cdot 7 & 17 \cdot 0 & 9 \cdot 4\end{array}$

It will be noted that when the load becomes excessive the efficiency rapidly falls away. This means that, although the effort may be continued as strenuously as before, and although the physiological cost of the effort remains at a very high level, the amount of external york done is reduced to a very low figure. The static element in the muscular effort has become dominant, and static expenditure is parasitic on dynamic work. The more static the work becomes the greater is the fall in the efficiency. Personally $I$ am of the opinion that the severity of muscular work, qua the organism as a whole, is a function of the static component of the effort made. Fatigue, i.e. inability to carry on, is more readily induced by static work than by either positive or negative work. The following figures, from experiments which I have carried out with Miss Bedale and G. McCallum, show clearly this diminution in efficiency as the static element in the work is increased :

TABLE IV.

\begin{tabular}{|c|c|c|c|}
\hline Pulls per min. & Kgm. per min. & $\begin{array}{c}\text { Cost in grm. cals. } \\
\text { per kgm. p. sq. m. }\end{array}$ & $\begin{array}{c}\text { Net Efficiency } \\
\text { per cent. }\end{array}$ \\
\cline { 2 - 4 } 32 & 40 & I6 & $8 \cdot 0$ \\
I2 & 15 & I7 & $7 \cdot 5$ \\
6 & $7 \cdot 5$ & 20 & $6 \cdot 0$ \\
4 & $5 \cdot 0$ & 31 & $3 \cdot 0+$ \\
3 & $3 \cdot 75$ & 38 & $3 \cdot 0$ \\
2 & $2 \cdot 5$ & 68 & $2 \cdot 0-$ \\
I & $1 \cdot 25$ & 146 & $1 \cdot 0$ \\
\hline
\end{tabular}

Very closely allied with the rate of working is the rhythm with which the work is performed. Although they are not identical phenomena, they are so closely related that the habit of work may be considered along with rhythm. Every one is well aware that once a rhythm, or the proper co-ordination in the play of a set of muscles in the performance of some definite act, is mastered, not only is the energy expenditure reduced by the exclusion of numerous extraneous muscular activities, but there is an actual enhancement of the ease with which we perform the specified act. It is not a mere question of rate. In a series of experiments which I carried out with Burnett, the subject, working on a specially geared ergometer, was allowed to select his own rate of working, the load being varied from nothing to 4 kilos. At each change of load the subject was directed either to work rapidly or very slowly, and after a period of such work was told to adopt the rate he liked best. As the following table (Table V.)

TABLE V.

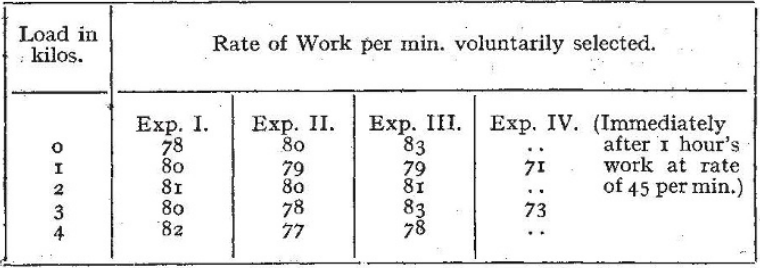

shows, the rhythm of work was practically identical for all loads. This occurred under all conditions; provided the working spells were not of too long duration. If the work were continued over a long period, the rhythm tended to alter, to increase in speed, and if the subject became really tired, periods of rapid movement alternated with periods of slow movement.

The rhythm adopted, although it may suit the worker, is not of necessity the series of muscle movements which lead to the least expenditure of energy

NO. $276 \mathrm{I}$, VOL. I IO] 
Most probably the rhythm selected is only in small part due to the worker's physical configuration; in greater part it is evolved in imitation of some more experienced or older worker. The average workman is not so much concerned with the diminution of the physiological cost in the performance of a given act as in the reduction of conscious effort. It is not, of course, suggested that the methods adopted by workers independently are the perfect methods, and that proper investigation will not discover better and easier methods of performing certain given operations. If newer and more economical methods are to be developed and brought into operation, the only real chance will be to segregate the newer young workers.

There is good evidence, that of Muscio, for example, that both resting and working, in addition to the individual muscle rhythm, there is a definite variation in the course of the day in the capacity to carry out work; that, in other words, a diurnal rhythm exists. There is a certain amount of evidence also in favour of the view that a seasonal rhythm exists. Further, when efficiency is measured in terms of output, it is found that there is a definite rhythm in output during the course of the working day and of the working week. This type of curve is not peculiar to any one industry. The total weekly output curve with the low Monday effect and the sharp fall on Saturday resembles in general shape the daily output curve. The main point about these curves is that they seem to demonstrate the absence of progressive fatigue from overwork, which would have been deduced had there been a sharp rise at the commencement of the week, followed by a steady fall.

The third of the potent factors in the control of fatigue is rest. If work is done, rest is ultimately imperative. Rest not merely relaxes the muscle, allowing a more thorough and complete removal of the waste products and a more abundant supply of oxygen, but it removes the strain of attention. Rest is best obtained, not by simple quiescence, but by change of posture ; slow movement of another type to that which produced the fatigue will, unless the organism is tired practically to complete exhaustion, give the most beneficial results.

So far, little attention has been paid to the duration of the rest period in relation to the work done. As a general rule, it may be said that, in the majority of occupations, although the hours of labour are continuous, the actual spells of hard manual work are discontinuous, either due to the fact that certain operations are intermittent in their severity, that supplies of material are not constant, or that, if these more or less natural conditions do not operate, rests at irregular intervals are deliberately taken by the operative. So far as I am aware there is only one type of hard work where a definite rest period is laid down as part of the exercise, namely, in Army route marching.

So much, then, for the ordinary effector factors. There are many other factors directly concerned with the efficient action of the organism, some directly influencing the internal economy of the body, others acting more indirectly on the organism from the environment,

One of these factors is the state of the nutrition. It may be definitely stated that an insufficient intake of food or the consumption of poor or inadequate food is one of the chief sources of general inefficiency. The capacity of the body to store reserve food material which will meet the daily demands for energy and leave a surplus is another of the vital factors of safety. The much more important problem is unfortunately only too common, the influence of chronic undernutrition, a condition which lowers efficiency, not merely in the actual performance of muscular work, but by inducing an increased susceptibility to disease. This is a question which has never received the attention which its importance demands, largely on account of the immense difficulties of carrying out the investigation in a practical manner. As the direct result of the war, we have the records of at least two sets of observers. Benedict and his co-workers investigated the problem, using a group of twelve men, comparing them with a similar group drawn from the same class. In the experimental group the food intake was reduced, so that there was a loss of $x 2$ per cent. of the body weight. Although the experiment was carried on for more than four months, the diminution in muscle power, so far as laboratory tests were concerned, was not great. The subjective impression, however, of the subjects was that they felt weaker and less capable.

The other recorded experiment is that of the condition in Germany during the war years. A general statement of the effects of the blockade is contained in a long document prepared by the German Government (dated December I9I8). Admittedly the document was prepared for a specific purpose ; but, after making all allowances, the record of the far-reaching effects of chronic underfeeding is valuable. Apart from the increased death rate, the increased liability to disease, and the slow recovery from the attacks of disease, the document definitely states that the working capacity of the people was reduced by at least onethird. Evidence would also indicate that it is not only the quantity but the quality of the food consumed which plays a part in the fitness of the individual to perform hard muscular work.

Another factor which plays an enormous rôle in the general efficiency is the response of the organism to the multiple psychic imponderabilia which compose such a large part of the average environment. When we are dealing with the efficiency of the human organism, male and female, we are dealing with individuals whose performance is neither uniform throughout the year nor from week to week, nor even from hour to hour. We have to deal with an organism, as I have already mentioned, which is not only under physical control, but is very responsive to psychic influences. Man is, in the main, a psychic chameleon.

In this connexion monotony of work must be considered. Although there may be a close relationship between monotony and fatigue, as generally recognised, they are not identical. The temperament of the operative plays an enormous part in determining whether or no any particular operation is a monotonous one. As Munsterberg has shown, it is extremely difficult, if not impossible, for an outsider to determine what is a monotonous operation.

There are many other factors which play a definite 
and important rôle in the maintenance of efficiency, such as lighting, heating, ventilation, the mode of life led by the worker outside his definite hours of labour, his housing, etc. Many of these factors have been partially examined. Thus Leonard Hill has carried out a great deal of valuable work on the influence of the cooling power of the air. Vernon has collected much interesting evidence, which shows that there is a very definite relation between the efficiency, as measured by output, and the temperature of the working place. The output in the hottest weather was about 30 per cent. below that when the weather was coldest. He also observed an apparent connexion between the relative humidity of the air and the efficiency of the worker. The efficiency, as might have been expected, was apparently greatest when the relative humidity was low. Elton has reported on the influence of lighting in silk weaving. He found that the output was lowest when artificial light was used. He stated that even when electric light of sufficient intensity was used, the output was about Io per cent. lower than the daylight value. The actual equipment of the factories, the provision of seats of suitable size, height, etc., the design of the machines, and so on, all play their part, as is shown by the many records, particularly from the United States.

In other words, the real over-all industrial efficiency of the worker cannot be causally related to any single factor. It is not the mere capacity of the individual to perform so many kilogram-metres of work in a given time with the smallest expenditure of energy. The quest of efficiency calls for the closest and most intimate co-operation between the scientific investigator, the employer, and the employee, and it can only be satisfactorily attacked when mutual distrust of motives, capacities, and methods is stilled.

\title{
The Total Solar Eclipse of September 2I.
}

\author{
By Dr. A. C. D. Crommelin.
}

$\mathrm{T}^{\mathrm{H}}$ E failure of the Christmas Island eclipse expedition is a great astronomical disappointment. Messrs. Jones and Melotte have devoted ten months or more to it, and hoped to secure useful photometric results for connecting the northern and southern stellar magnitude scales in addition to the eclipse work. The climate, however, proved unexpectedly unfavourable, and practically nothing could be done.

On the other hand, the conditions appear to have been ideal right across Australia, and enthusiastic reports have come from Wollal (West Coast), Cordillo Downs (centre), and Goondiwindi and Stanthorpe (Queensland). The Einstein problem was studied at Wollal by the Lick Observatory party under Prof. Campbell, and that from Toronto under Prof. Chant. Mr. Evershed also finally selected this station in preference to the Maldives, and is believed to have undertaken the same investigation, in addition, doubtless, to spectroscopic work. Prof. Dodwell, the Government Astronomer at Adelaide, had the use at Cordillo Downs of a tower telescope lent by the Lick Observatory for the Einstein problem; the New South Wales astronomers were in Queensland and did some spectroscopic work; they intended also to make Einstein investigations, but the telegrams do not allude to these.

It is well to point out that the test of the Einstein theory does not depend wholly on the results of this eclipse. The plates secured in the I9I9 eclipse at Principe and Sobral settled definitely that at least the half-shift was present, while the two cameras with the best definition gave values very close to the Einstein value. Further, the star-field in that eclipse was the best along the whole extent of the ecliptic, the stars in the present eclipse being much fainter. There are, however, two circumstances that should add weight to this eclipse: (I) that some of the observers were pointing directly on the stars, avoiding the use of a cœlostat or other mirror ; (2) that the plan was being tried of photographing another star-field during totality, thus obtaining an independent scale-value for the plates, which gives a much larger coefficient to the Einstein displacement in the equations of condition.

Probably weeks or months must elapse before the Einstein results are to hand.

The corona is said to have had four long streamers, one extending to three solar diameters, which is more than the average, though by no means a record.

Prof. Chant reports that the shadow bands were photographed. Prof. Kerr Grant, of Adelaide University, made measures at Cordillo by the photoelectric cell of the relative brightness of the sun and the corona. The results, with this very sensitive instrument, should be more trustworthy than previous determinations.

The next two total eclipses (r923, September, and I925, January) are visible in the United States; 1926, January, in Sumatra, etc., and 1927 in England and Norway.

\section{Obituary.}

\section{Prof. Alexander Smith.}

ALEANDER SMITH, emeritus professor of chem$A$ istry in Columbia University, New York, died in Edinburgh on September 8, aged fifty-seven, Smith was born in Edinburgh, and entered the University there in 1882, where he studied mathematics under Chrystal, natural philosophy under Tait, and chemistry under Crum Brown, graduating as B.Sc. in 1886 . During the following three years he attended the University. of Munich, working in Baeyer's laboratory, chiefly under the direction of Claisen, and obtained the degree of Ph.D. in I889.

After a year spent as assistant in the chemistry department of the University of Edinburgh, Smith was offered the chair of chemistry and mineralogy in Wabash College, Indiana, a post which he held for four years. In 1894 he became assistant professor of 